\title{
ANÁLISE COMPARATIVA DA LEGISLAÇÃO FEDERAL DE PROTEÇÃO DA MULHER CONTRA VIOLÊNCIA DOMÉSTICA NO BRASIL E NOS ESTADOS UNIDOS
}

\section{COMPARATIVE ANALYSIS OF FEDERAL LEGISLATION ON THE PROTECTION OF WOMEN AGAINST DOMESTIC VIOLENCE IN BRAZIL AND THE UNITED STATES}

\author{
Julia Lopes Braga* \\ Laysla Oliveira Santos ${ }^{* *}$
}

\begin{abstract}
RESUMO
A violência doméstica persiste em todo o cenário global desde a antiguidade e implica em graves consequências que afetam todas as esferas da sociedade. Assim, o artigo objetiva estudar comparativamente as legislações brasileiras e norte-americanas contra violência doméstica, com foco central em identificar as semelhanças e diferenças principais entre a Lei Maria da Penha de 2006 e o Violence Against Women Act criado em 1994. Os elevados números de casos de violência doméstica no Brasil e nos Estados Unidos ressaltam a necessidade do estudo comparado das estratégias existentes para o combate de tal prática, visto que possibilita uma visão mais ampla dessa matéria legislativa por meio do conhecimento de diferentes soluções adotadas por diferentes países. O estudo será realizado seguindo uma metodologia qualitativa baseada em pesquisas bibliográficas, documentais e dados de organizações brasileiras e internacionais. Ao fim da análise, é possível reconhecer diversas semelhanças e diferenças entre as referidas leis.
\end{abstract}

Palavras-chave: Violência doméstica. Brasil. Estados Unidos. Lei Maria da Penha. Violence Against Women Act.

\begin{abstract}
Domestic violence has persisted throughout the global scenario since antiquity and implies serious consequences that affect all spheres of society. Thus, the article aims to study comparatively the Brazilian and North American domestic violence legislation, with a central focus on identifying similarities and main differences between the Lei Maria da Penha of 2006 and the Violence Against Women Act created in 1994. The high numbers of cases of domestic violence in Brazil and the United States underscore the need for the study in relation to the strategies adopted to combat such practice, since it allows a broader view of this legislative matter through the knowledge of different solutions adopted by different countries. The study will be carried out following a qualitative methodology based on bibliographic, documentary research and data from Brazilian and international associations. At the end of the analysis, it is possible to recognize several similarities and differences between comparisons of the laws.
\end{abstract}

Artigo submetido em 04 de janeiro de 2021 e aprovado em 04 de março de 2021.

* Graduanda no curso de Direito na Universidade Federal do Espírito Santo. Email: juliabraga030@ gmail.com

** Graduanda no curso de Direito na Universidade Federal do Espírito Santo. Email: laysla38@gmail.com 
Artigo: Análise comparativa da legislação federal de proteção da mulher contra violência doméstica no Brasil e nos Estados Unidos

Keywords: Domestic violence. Brazil. United States. Lei Maria da Penha. Violence Against Women Act.

\section{INTRODUÇÃO}

Dados revelam que no ano de 2019 foram quase 1,2 milhões de casos de violência doméstica nos Estados Unidos (MORGAN, TRUMAN, 2020), e que, de todas as mulheres mortas nos EUA, um terço foi assassinada por parceiros íntimos (NOW, 2020), revelando um alto índice de violência familiar e seus graves desdobramentos. No Brasil, estatísticas divulgadas em estudo do IPEA (CERQUEIRA, MOURA, PASINATO, 2019) mostraram que em $25,9 \%$ dos casos de agressão contra mulheres, o cônjuge ou ex-cônjuge foi o agressor, e ainda que em $43,1 \%$ do total de casos de violência contra mulher, a agressão aconteceu em sua própria residência.

Os altos números de casos de violência doméstica no Brasil e nos Estados Unidos revelam a importância de se fazer um estudo à luz comparativa, uma vez que possibilita o entendimento do tamanho da problemática e do quanto a temática é relevante, não apenas no Brasil, mas em plano global. Dessa forma, é fundamental analisar as estratégias existentes para o combate da violência intrafamiliar em outros países, a fim de ampliar a visão legislativa com base nas soluções encontradas no âmbito internacional. Busca-se, assim, responder a seguinte questão: quais as medidas previstas legalmente nos Estados Unidos e no Brasil relativamente à violência doméstica?

A partir dessa questão, o presente artigo pretende identificar quais os principais aspectos diferentes e correspondentes entre as legislações federais brasileiras e estadunidenses por meio de uma metodologia qualitativa baseada em coletas documentais e bibliográficas de origem nacional e internacional. A pesquisa será desenvolvida com método comparativo, com o objetivo de analisar e comparar institutos legislativos de dois países sobre violência doméstica, com foco central na Lei Maria da Penha do Brasil, de 2006, e no Violence Against Women Act dos EUA, criado em 1994.

O presente trabalho está dividido em três capítulos: o primeiro, que abordará as principais questões que norteiam a complexa conjuntura da violência doméstica; o segundo, que trará as informações centrais acerca desse tema na legislação brasileira, com especial consideração à Lei 11.340/06; e o terceiro, que apresentará as particularidades de uma lei estadunidense que protege a mulher contra violência.

\section{A PERPETUAÇÃo históriCA Da VIOLÊNCIA DOMÉSTICA E SEUS PRINCIPAIS ASPECTOS}

A violência contra a mulher, perpetuada em todas as partes do mundo, encontra no âmbito privado dos lares e nos relacionamentos íntimos um imenso espaço de atuação. É dentro da esfera doméstica que persiste um dos lugares mais visíveis em que reside a relação de dominação masculina sobre o feminino (BOURDIEU, 2020, p.16). A violência doméstica consiste em um padrão de comportamentos exercidos por um parceiro íntimo, a fim de exercer controle sobre a outra pessoa do relacionamento, seja por meio de violência física, coação, ameaças, intimidações, abusos sexuais, emocionais ou econômicos. Nesse sentido, ganha destaque dados do DataSenado que informam que, entre as mulheres pesquisadas que já sofreram de violência, " $65 \%$ foram agredidas por seu próprio parceiro de relacionamento, ou seja, por marido, companheiro ou namorado" (BRASIL, 2013, p.5), sem ser possível ignorar casos de agressões por ex parceiros de relacionamentos e outras pessoas do convívio familiar. 
"The group women has a collective social history of disempowerment, exploitation, and subordination extending to the present" (MACKINNON, 1991, p.1298). Nessa lógica, vê-se que a violência doméstica está longe de ser um fenômeno moderno e somente uma análise do papel da mulher na história é capaz de esclarecer as origens dessa mazela que ultrapassa os séculos. A ordem e dominação masculina é continuamente reproduzida desde que existem homens e mulheres (BOURDIEU, 2020, p.137), e as estruturas dessa dominação são resultadas de um trabalho histórico de reprodução, o qual foi produzido pela contribuição dos homens, das família, da igreja, das escolas e dos próprios Estados (BOURDIEU, 2020, p.64).

Por muito tempo, os direitos das mulheres foram injustamente suprimidos, e o exercício pleno das diversas práticas sociais era negado a elas, muito em função de retrógrados preconceitos sociais e culturais (BRASIL, 2019, p. 9). Sob essa perspectiva, observa Catharine Mackinnon (1991, p.1298) que essa privação de direitos da mulher, unida a sua exclusão da vida pública, a sua objetificação e às desigualdades econômicas baseadas no gênero contribuíram para uma desvalorização da dignidade das mulheres em todas as sociedades. Em vista disso, ressalta-se o importante papel das extensas lutas feministas contra esse cenário excludente e discriminatório, que conseguiram alcançar isonomia dos direitos em uma sociedade machista e patriarcal.

A compreensão das causas da violência contra a mulher é de suma importância para a conscientização pública e a erradicação dessa problemática (ZAGANELLI; SALARDI, 2020, p.54,). Essencial, pois, pontuar e desenvolver o entendimento dos motivos que permitem a perpetuação da violência doméstica. Com efeito, verifica-se a banalização dessa prática e os entraves para reconhecê-la como um fator que dificulta seu combate. Nesse aspecto, pontua Danielle Martins Silva (2008) que a violação dos direitos das mulheres em situações de proximidade e dependência em relação ao agressor, seja econômica ou emocional, pode não ser identificada como um ato de violência, haja vista que "sua ocorrência resta assentada no senso comum social como algo corriqueiro e sem importância" (SILVA, 2008). Destaca-se que há uma compreensão social, ainda presente na sociedade apesar de sinalizar mudanças, de uma máxima popular de que "em briga de marido e mulher, ninguém mete a colher" (BRASIL, 2019, p. 27).

Consoantemente, observa Pierre Bourdieu (2020, p.22), que "a divisão entre os sexos parece estar "na ordem das coisas", como se diz por vezes para falar do que é normal, natural, a ponto de ser inevitável". Consequentemente, essa violência banalizada no ambiente privado deixa de ser identificada pelas próprias vítimas, pela sociedade e até mesmo pelos Estados, que demoram em tomar medidas efetivas para preveni-la e eliminá-la. Nos lares familiares, principal espaço de ocorrência de violência doméstica, é onde mais se reproduz as relações de dominação masculina, onde "se impõe a experiência precoce da divisão sexual do trabalho e da representação legítima dessa divisão" (BOURDIEU, 2020, p.141).

Outro fator responsável, em muitos casos, pela continuidade da violência doméstica se refere à dependência econômica feminina, uma vez que o controle das riquezas apenas pelo homem pode gerar uma ideia de autoridade nas tomadas de decisões dentro das famílias e submeter as mulheres a situações de vulnerabilidade econômica, reforçando a dominação e dificultando a saída delas da relação de violência. Contexto que se evidencia quando se tem que "o acesso das mulheres ao trabalho profissional é fator preponderante ao seu acesso ao divórcio" (BOURDIEU, 2020, p.67-68).

\footnotetext{
${ }^{1}$ As mulheres têm uma história social coletiva de desempoderamento, exploração e subordinação que se estende até o presente (tradução nossa).
} 
Artigo: Análise comparativa da legislação federal de proteção da mulher contra violência doméstica no Brasil e nos Estados Unidos

Além disso, constata-se que a existência de leis que objetivam proteger as mulheres de violência doméstica é fundamental, entretanto, a falta de efetividade dessas regras também contribui para o continuísmo dessa violência. Sob essa ótica, vê-se que há uma falta de regulamentação e de procedimentos claros para a aplicação das leis, falta de capacitação profissional adequada para fornecer plena assistência às vítimas, como assistência policial, jurídica e de saúde, cenário que desencoraja mulheres a relatar casos (UN WOMEN, 2006, p.101).

Em concordância, dados da Secretaria de Transparência DataSenado informam que 30\% de mulheres vítimas de violência que realizaram denúncia avaliaram o atendimento recebido na delegacia como ruim ou péssimo (BRASIL, 2013, p.8). E apontam o medo do agressor, a vergonha e a preocupação com os filhos também como fatores que desmotivam mulheres a denunciar. Outros elementos apresentados como motivadores de violência doméstica são: consumo de álcool, ciúmes, traição, falta de dinheiro e vícios (BRASIL, 2013, p.38).

A violência doméstica possui um caráter duplamente cruel, "pois de um lado se caracteriza como uma violência de gênero e de outro se materializa no ambiente que deveria ser antes de tudo um lugar seguro e acolhedor" (SILVA; SEABRA; JUNIOR, 2016, p.316). A violência no ambiente familiar, que deveria ser um lugar de proteção, provoca inúmeras consequências, tanto físicas, como emocionais e patrimoniais, que afetam não apenas as vítimas, mas toda a estrutura da família. Entre as graves consequências possíveis, têm-se as lesões, os transtornos pós-traumáticos, a contração de doenças sexualmente transmissíveis, o desenvolvimento de depressão e o feminicídio. Ademais, segundo a United Nations Entity for Gender Equality and the Empowerment of Women (UN WOMEN, 2006, p.59), mulheres agredidas têm maior risco de ter problemas reprodutivos, bem como a adquirir vícios. Além das vítimas, esse tipo de violência implica em desafios para todos os membros das famílias, muitas crianças, por exemplo, que vivem em situação de violência familiar, têm sua saúde e desempenho educacional afetados (UN WOMEN, 2006, p.62).

Segundo o art. $7^{\circ}$ da Lei Maria da Penha, $n^{\circ}$ 11.340/06, a violência doméstica pode ser subdividida em violência física, psicológica, sexual, patrimonial e moral. A violência física é definida como qualquer ação que ofenda a integridade física e corporal. Violência psicológica é qualquer ação que resulte em algum tipo de dano emocional e psicológico, como humilhação, constrangimento, controle de ações e decisões, intimidação e chantagem. A violência sexual pode ser definida como ações que obriguem a mulher a assistir ou participar de alguma relação sexual em que ela não queira ou não esteja consciente para concordar ou negar, além do impedimento ou interferência na decisão da mulher sobre métodos contraceptivos, aborto e gravidez. Violência patrimonial é controlar ou reter dinheiro e bens, danificar bens e objetos de trabalho, interferir no ambiente e instrumentos de trabalho e destruir documentos de maneira parcial ou total. Por fim, a violência moral é qualquer tipo de humilhação pública, exposição da vida íntima do casal, calúnia, acusação e injúrias (BRASIL, 2006).

A violência doméstica não atinge somente um grupo específico de mulheres ao redor do mundo. Extremamente comum, é vista como uma pandemia global sem limites que faz vítimas de todo tipo de classe social, raça e nacionalidade (ZAGANELLI, SALARDI, 2020, p.50). Entretanto, assim como outras problemáticas sobre violência, também existem grupos específicos que são mais vulneráveis à violência doméstica. Nos Estados Unidos, por exemplo, mulheres mais novas (entre 20-24 anos), mulheres de renda mais baixa e afro-americanas sofrem mais com violência doméstica do que outras. Quanto mais pobre a comunidade em que a mulher vive, maior o índice de violência (NOW, 2020), uma vez que a escassez de recursos econômicos e a falta de independência financeira podem reduzir a capacidade da mulher de tomar decisões e agir (UN WOMEN, 2006, p.34). No Brasil, de maneira análoga, as mulheres 
que sofrem mais com a violência doméstica são as com menor nível de instrução, pretas ou pardas (BRASIL, 2013, p.3).

Para a erradicação da violência doméstica faz-se necessário a vontade e o compromisso dos Estados para que medidas de proteção tenham prioridade, essa vontade política pode ser expressa de diferentes formas, incluindo, principalmente, legislações, planos de ação nacionais e esforços para atenuar a impunidade (UN WOMEN, 2006, p.22). No Brasil, tal expressão se verifica, com maior relevo, na Lei Maria da Penha de número 11.340/06, aprovada em 2006 sob governo do então presidente Luiz Inácio Lula da Silva, que aborda todo tipo de violência doméstica e suas particularidades e penalizações (BRASIL, 2006). E nos Estados Unidos da América, no Violence Against Women Act (VAWA), uma lei federal aprovada pelo Congresso americano em 1994, sob o governo do então presidente Bill Clinton, e que passou por várias reautorizações desde então. Dessa forma, essas leis e outras legislações brasileiras serão comentadas no presente artigo a cunho de contextualização histórica, mantendo foco principal na Lei ${ }^{\circ} 11.340$, que é a lei referência no assunto no Brasil.

Nesse sentido, o próximo capítulo se inicia com os principais aspectos que envolvem a Lei ${ }^{\circ}$ 11.340/2006, popularmente conhecida como Lei Maria da Penha.

\section{PROTEÇÃO LEGISLATIVA CONTRA A VIOLÊNCIA DOMÉSTICA NO BRASIL}

De maneira introdutória, é necessário ressaltar que o estudo da história da mulher brasileira nos revela raízes patriarcais no pensamento e comportamento social, assim como na legislação. As Ordenações Filipinas, que vigoraram no período colonial brasileiro, normalizaram o pensamento de dominação masculina, que pode ser observado na não imputação de pena caso o marido aplicasse qualquer tipo de castigo físico à sua esposa e filhos (PORTUGAL, 1595).

Um pouco mais recente, o Código Civil de 1916 continua a reforçar essa cultura de enorme discrepância entre os direitos do homem e da mulher, onde o sexo feminino era visto como relativamente incapaz à realização de certos atos, tendo sempre que se submeter à vontade do marido, ou figura masculina (SILVA, SEABRA, JUNIOR, 2016, p.308). O Artigo 242 dessa codificação revela algumas das restrições: a mulher não podia, sem autorização do marido: Ipraticar os atos que este não poderia sem o consentimento da mulher; II- alienar ou gravar de ônus real os imóveis de seu domínio particular, independentemente do regime de bens; IIIalienar os seus direitos reais sobre imóveis de outro; IV- contrair obrigações que possam importar em alienação de bens do casal. (BRASIL, 1916). Em vista disso, é possível perceber que a problemática da violência doméstica no Brasil possui bases antigas, profundas e sólidas de inferiorização da mulher.

Entretanto, nota-se que alguns avanços nos direitos da mulher foram alcançados. O Código Penal demonstra o primeiro despertar normativo com relação à violência contra a mulher, visando à punição para diversos crimes dessa categoria (BRASIL, 1940). Em 1962, o Estatuto da Mulher Casada, concedeu alguns direitos à mulher, como o compartilhamento do pátrio-poder, fazendo com que o homem deixasse de ser o chefe absoluto do lar, indicando que a lei já não enxerga a mulher da mesma forma que antes. Assim, é possível ver um longo caminho nas legislações de violência contra a mulher até o cenário atual, com a Lei Maria da Penha.

As desigualdades de gênero são consequências de uma construção social, de um sistema de dominação que enxerga como natural a inferiorização feminina e que contribui para formar um campo fértil para a violência contra a mulher, criando um cenário de impunidade que prevalece por séculos (FREIRE, 2004, p.14). A problemática da violência contra a mulher 
Artigo: Análise comparativa da legislação federal de proteção da mulher contra violência doméstica no Brasil e nos Estados Unidos

começa a ganhar visibilidade por volta de 1970, com manifestações do movimento feminista, e começa a ser visto como violação dos direitos humanos (BRASIL, 2020, p. 20).

Assim, em consonância com as reivindicações, a Lei de número 11.340/2006, comumente chamada "Lei Maria da Penha" nasce como resultado do caso Maria da Penha vs. Estado brasileiro. Contexto em que o Brasil foi denunciado na Comissão Internacional de Direitos Humanos por ter sido omisso no caso concreto de Maria da Penha e falhado com o dever de condenar todo tipo de violência contra a mulher assumido na "Convenção do Belém do Pará", a qual é uma convenção Interamericana para prevenir, punir e erradicar a violência contra a mulher, adotada em 1994 (BRASIL, 2020, p. 13).

O caso concreto denunciado é de Maria da Penha Maia Fernandes, uma professora universitária de classe média que sofreu duas tentativas de homicídio por seu marido, situação em que ficou paraplégica pelo tiro disparado na primeira tentativa, se tornando símbolo da violência doméstica no Brasil. Após as intervenções internacionais, seu marido foi punido em 8 anos de prisão, e a Lei de número 11.340/2006 foi aprovada contando com grande participação de diversos setores do Estado e da sociedade civil (BRASIL, 2019, p. 27). A Lei teve por escopo oferecer tutela integral à mulher vítima de violência doméstica, não só visando a punição aos agressores, como também protegendo as vítimas, além de suprimir, de certa forma, a estrutura patriarcal e sexista da sociedade brasileira. (SILVA; SEABRA; JUNIOR, 2016, p. 321).

Em primeiro lugar, para entender a lei 11.340/06 por completo, é necessário entender o conceito de "violência doméstica" que ela estabelece. Violência doméstica e familiar é configurada como qualquer ação ou omissão baseada no gênero que lhe cause morte, lesão, sofrimento físico, sexual ou psicológico e dano moral ou patrimonial, no ambiente doméstico (espaço de convivência permanente entre pessoas tendo vínculo familiar ou não, inclusive esporadicamente agregadas), no âmbito da família (comunidade formada por indivíduos que são ou se consideram parentes por laços biológicos, afinidade ou vontade) ou em qualquer relação íntima de afeto (na qual o agressor já conviveu ou convive com a vítima, independentemente da coabitação) (BRASIL, 2006). Outrossim, como já citado anteriormente a norma divide a "violência doméstica" em cinco tipos de violência: violência física, psicológica, sexual, patrimonial e moral especificando e contextualizando cada tipo (BRASIL, 2006).

De acordo com o Ministro do Superior Tribunal Federal, Ayres Britto, a norma deve sair em defesa dos segmentos sociais historicamente desfavorecidos, como é o caso das mulheres (BRASIL, 2019, p. 17). Em vista disso, com o objetivo principal de coibir e prevenir a violência doméstica e familiar, a Lei $n^{\circ} 11.340 / 2006$ ainda dispõe sobre a criação de Juizados Especiais e estabelece medidas protetivas para mulheres vítimas dessa violência (BRASIL, 2006).

Em consonância com Pierre Bourdieu (1995, p. 147), que afirma que as instituições escolares e educacionais têm função decisiva na transformação do estereótipo de inferioridade do gênero feminino, a Lei $\mathrm{n}^{\circ}$ 11.340/06 traz medidas preventivas, como o inciso $\mathrm{V}$ do artigo $8^{\circ}$, que estabelece a realização de campanhas educativas de prevenção da violência doméstica e familiar contra a mulher, voltadas ao público escolar e à sociedade, e a disseminação desta Lei e dos instrumentos de proteção aos direitos humanos das mulheres, como também a promoção de programas educacionais que disseminem valores éticos e de respeito com perspectiva de gênero, raça e etnia, do inciso VI (BRASIL, 2006).

É importante ressaltar alguns artigos no âmbito de mecanismos de assistência à vítima que a Lei Maria da Penha traz, como o artigo $9^{\circ}$, o qual afirma que o juiz deve assegurar à mulher vítima de violência a manutenção do vínculo trabalhista no inciso II e encaminhamento 
à assistência judiciária no caso de separação, divórcio, anulação de casamento ou dissolução de união estável no inciso III. (BRASIL, 2006).

Ademais, a Lei estabelece as "Medidas Protetivas de Urgência", que são de responsabilidade do juiz e devem ser direcionadas, em até 48 horas após o recebimento do pedido da vítima, ao agressor, que podem incluir: a suspensão de posse ou restrição do porte de armas, inciso I; o afastamento do lar, domicílio, local onde há convivência com a vítima, inciso II; a proibição de aproximação e contato à vítima, inciso III (BRASIL, 2006). Em caso de descumprimento de decisão judicial que defere as medidas protetivas de urgência por parte do agressor, o artigo 24-A traz pena de detenção de três meses a dois anos. (BRASIL, 2006).

Além da punição para descumprimento de medida protetiva de urgência, a Lei promoveu alterações no Artigo 129 do Código Penal: "ofender a integridade corporal ou saúde de outrem" (BRASIL, 1940). O parágrafo 9 traz detenção de três meses a 3 três anos (BRASIL, 2006) caso a lesão seja praticada por cônjuge, companheiro(a), irmão(a), descendente, ascendente, alguém que conviva ou tenha convivido com a vítima. $O$ parágrafo 10 , apesar de ter sido incluído no Código Penal antes do sancionamento da Lei Maria da Penha, também diz respeito a violência doméstica, e traz aumento de pena em até um terço em caso de lesão corporal grave ou seguida de morte que acontecer nas circunstâncias domésticas. Por fim, cabe citar que a Lei de número 11.340/2006 traz detalhes também sobre outros assuntos de elevada importância, como o atendimento policial que a vítima tem direito, estabelece capacitação permanente para autoridades que lidam com mulheres agredidas, a atuação do ministério público no caso concreto, o direito à assistência jurídica gratuita à vítima e a promoção de estudos e pesquisas sobre violência familiar. (BRASIL, 2006).

A Ministra do Superior Tribunal Federal, Rosa Weber, reafirma a fala da Carta das mulheres aos constituintes, de 1987, que diz que o exercício pleno da cidadania para as mulheres significa, além da representação e da voz ativa na vida pública, a dignidade na vida cotidiana, como direito à segurança e à uma vida familiar sem traumas garantida pela Lei (BRASIL, 2019, p.14). Sob essa perspectiva, é válido comentar acerca de outra legislação, além da Lei Maria da Penha, que tem como objetivo garantir segurança à mulher brasileira: a Lei do Feminicídio ${ }^{\circ}$ 13.104/2015.

Acerca desse assunto, é necessário entender, primeiramente, que feminicídio é o assassinato de mulheres de maneira específica pela condição de ser mulher, cuja motivação pode ser ódio, prazer, desprezo ou um sentimento de propriedade. Segundo o Instituto de Pesquisa Econômica Aplicada (IPEA), no período de 2012 a 2017, houve um aumento de 17,1\% no índice de homicídio feminino dentro das suas residências, em outras palavras, feminicídio (CERQUEIRA, MOURA, PASINATO, 2019). Assim, em um país com taxas que crescem dessa forma, a criação de uma lei específica para esse assunto foi essencial.

A Lei de número 13.104 foi sancionada em 2015 pela então presidente Dilma Rousseff, e promove mudanças no artigo 121 do Código Penal brasileiro, sobre matar outrem. O inciso VI traz: "contra mulher por razões de condição de sexo feminino", com pena de reclusão de doze a trinta anos. (BRASIL, 2015). O parágrafo 2-A traz: "considera-se que há razões de condição de sexo feminino quando o crime envolve": inciso I: "violência doméstica e familiar"; inciso II: "menosprezo ou discriminação à condição de mulher". (BRASIL, 2015). Além disso, é válido ressaltar que há aumento de pena de $1 / 3$ até metade se $\mathrm{o}$ feminicídio for em descumprimento das medidas protetivas de urgência, previstas nos incisos I, II e III do artigo 22 da Lei ${ }^{\circ}$ 11.340/2006, inciso IV do parágrafo 7 do artigo 121 do Código Penal (BRASIL, 2018).

O próximo capítulo terá foco nas soluções adotadas pelos Estados Unidos no que diz respeito à violência doméstica, com especial atenção ao Violence Against Women Act. 


\section{LEI FEDERAL ESTADUNIDENSE CONTRA A VIOLÊNCIA DOMÉSTICA: VIOLENCE AGAINST WOMEN ACT}

Em uma primeira abordagem, é necessário compreender que a forma de elaboração do direito não é uniforme nos diversos países. Diferentemente do Brasil, que adota o sistema civil law, nos Estados Unidos da América (EUA) o direito é da família da common law, ou seja, o direito se revela muito mais pelos usos e costumes do que pelas leis (REALE, 2018, p.141142).

Entretanto, apesar do direito norte-americano ser reconhecido como um direito jurisprudencial, "é necessário saber que, apesar destes sentimentos, a realidade é constituída por uma grande diversificação dos dois direitos" (DAVID, 2002, p.458). Assim, destaca-se que, no direito americano, o papel das leis é de relevo, sendo o mais importante o papel da Constituição Federal, "dotada de uma Declaração dos Direitos (Bill of Rights), que é a própria base das instituições americanas e o fundamento das liberdades públicas (civil rights) nos Estados Unidos" (DAVID, 2002, p.477).

Nesse sentido, René David (2002, p.505) ressalta que a proliferação de leis nos Estados Unidos é considerável, e "o recente desenvolvimento das tendências dirigistas, tanto nos Estados Unidos como na Inglaterra, tende a aumentar a importância da lei; a evolução do direito é, doravante, em múltiplos e importantes setores, comandada pela legislação" (DAVID, 2002, p.477). Além disso, sendo os Estados Unidos um país federalista, é necessário que o direito concilie interesses da nação e de cada Estado (DAVID, 2002, p.457), sendo assim, no que tange à proteção da mulher contra violência nos EUA, há leis estaduais e federais.

Nesse panorama, no que diz respeito à ocorrência de violência doméstica, a maioria dos casos é tratada pelas autoridades estaduais e locais, e as leis federais são aproveitadas quando os ganhos de sua aplicação forem mais vantajosos (ESTADOS UNIDOS DA AMÉRICA, 2020). Cada Estado, território ou reserva indígena dos Estados Unidos decide como definir a violência doméstica e como será a aplicação de suas leis (WOMENSLAW.ORG). Desse modo, a abrangência da proteção dessas leis pode variar para cada Estado. A lei federal estadunidense de maior importância na proteção de mulheres em situação de violência é o Violence Against Women Act (VAWA).

De acordo com o National Domestic Violence Hotline ${ }^{2}$, a criação do Violence Against Women Act foi um marco legislativo que mudou a forma como a nação lidava com a violência doméstica, violência no namoro, agressão sexual e perseguição nos Estados Unidos. O VAWA foi a primeira lei federal aprovada a reconhecer a violência doméstica e a agressão sexual como crimes, aprimorando substancialmente a resposta do sistema às vítimas (DOCHELER, 2020).

Tal lei foi inicialmente introduzida no congresso norte-americano em 1990, pelo então presidente do U.S. Senate Judiciary Committee, Joe Biden ${ }^{3}$, contribuindo para dar relevo à questão em nível nacional (LAW, 2019), visto que deu visibilidade para uma questão que não recebia a devida atenção, nem social, nem governamental. O projeto de lei foi, então, após uma série de audiências nas quais foram ouvidos diversos especialistas, mulheres que foram vítimas de violência e uma variedade de autoridades, aprovado em 1994 pelo congresso (DOCHELER, 2020). O VAWA, sancionado pelo então presidente Clinton, foi incluído como Título IV no Violent Crime Control and Law Enforcement Act de 1994 (P.L. 103-322) (SACCO, 2019, p.2).

O desenvolvimento do VAWA foi resultado de décadas de elevadas taxas de violência contra mulheres no país. Na década de 60 , por exemplo, tais crimes mais que dobraram nos

\footnotetext{
${ }^{2}$ A National Domestic Violence Hotline é um canal de linha direita de assistência a vítimas de violência doméstica criado pelo próprio VAWA em 1994.

3 Joseph Robinette "Joe" Biden é o atual presidente eleito dos Estados Unidos da América.
} 
Estados Unidos, cenário que despertou grande preocupação social e pública, superando a visão da violência familiar como um assunto apenas privado (SACCO, 2019, p.1). Com efeito, muitas razões exigiam que o governo federal desenvolvesse mecanismos para combater a violência de gênero, bem como proporcionasse assistência às vítimas. Ademais, válido destacar que, quando o VAWA foi consolidado,

many states, territories, and tribes did not have sufficient laws or services to address violence against women, and, consequently, the federal legislation had to be carefully crafted to support the nationwide development of interventions and responses ${ }^{4}$ (DOCHELER, 2020).

Nesse contexto, antes da criação de uma lei federal sobre violência doméstica, muitos agressores mudavam de Estados com o intuito de evitar acusações. Dessa forma, entre os principais objetivos do VAWA, está a prevenção de crimes violentos contra a mulher, fornecer assistência às vítimas, desenvolver estudos sobre tais crimes e adequar as respostas governamentais a esses crimes, tanto no âmbito criminal, como nos de fornecimento de serviço social. Objetivos esses que a lei tenta atingir por meio, principalmente, de programas de subsídios federais que fornecem financiamento para governos estaduais, tribais, territoriais e locais, organizações sem fins lucrativos e universidades (SACCO, 2019). Mais de mil milhões de dólares já foram autorizados para fornecer apoio a esses programas, que visam, entre outras medidas, promover treinamento de autoridades, como policiais, promotores e juízes, prevenir abusos contra mulheres, estabelecer órgãos que atendam diretamente às mulheres em situação de violência e ampliar as pesquisas acerca desse tipo de crime (UN WOMEN, 2006, p.115).

Desse modo, vale ressaltar, a definição de violência doméstica dada pelo Violence Against Women Act.

The term "domestic violence" includes felony or misdemeanor crimes of violence committed by a current or former spouse or intimate partner of the victim, by a person with whom the victim shares a child in common, by a person who is cohabitating with or has cohabitated with the victim as a spouse or intimate partner, by a person similarly situated to a spouse of the victim under the domestic or family violence laws of the jurisdiction receiving grant monies, or by any other person against an adult or youth victim who is protected from that person's acts under the domestic or family violence laws of the jurisdiction ${ }^{5}$ (ESTADOS UNIDOS DA AMÉRICA, 1994) ${ }^{6}$.

Como anteriormente mencionado, o VAWA também trata da prática 'dating violence' (violência no namoro), a qual é conceituada como "violence committed by a person who is or has been in a social relationship of a romantic or intimate nature with the victim."7 (ESTADOS

\footnotetext{
${ }^{4}$ Muitos Estados, territórios e tribos não tinham leis ou serviços suficientes para lidar com a violência contra as mulheres e, consequentemente, a legislação federal teve que ser cuidadosamente elaborada para apoiar o desenvolvimento nacional de intervenções e respostas (tradução nossa).

${ }^{5} \mathrm{O}$ termo " violência doméstica " inclui crimes dolosos ou contravenções de violência cometidos por um cônjuge atual ou ex-cônjuge ou parceiro íntimo da vítima, por uma pessoa com quem a vítima tem um filho em comum, por uma pessoa que coabita ou coabitou com a vítima como cônjuge ou parceiro íntimo, por uma pessoa em situação semelhante ao cônjuge da vítima sob as leis de violência doméstica ou familiar da jurisdição que recebe verbas de subsídio, ou por qualquer outra pessoa adulta ou jovem pela qual a vítima é protegida dos atos dessa pessoa sob as leis de violência doméstica ou familiar da jurisdição (tradução nossa).

${ }^{6}$ O Violence Against Women Reauthorization Act of 2013 (P.L. 113-4) revisou a definição de violência doméstica especificamente para incluir "parceiros íntimos" além de "cônjuges atuais e ex-cônjuges".

7 Violência cometida por pessoa que mantém ou manteve relação social de natureza romântica ou íntima com a vítima (tradução nossa).
} 
Artigo: Análise comparativa da legislação federal de proteção da mulher contra violência doméstica no Brasil e nos Estados Unidos

UNIDOS DA AMÉRICA, 1994), considerando, para a determinação da relação, o tempo de duração do relacionamento, o tipo de relacionamento e a frequência de interação entre os envolvidos.

O Violence Against Women Act determinou, entre suas principais medidas, que as ordens de proteção emitidas pelos tribunais estaduais sejam reconhecidas por todos os outros Estados do país e permitiu a execução de processos federais para casos de violência doméstica e crimes de agressão sexual ${ }^{8}$. Ele também forneceu subsídios para que os Estados exijam a prisão obrigatória de abusadores e aprimorem os processos investigativos (LAW, 2019). Ademais, a lei instituiu como crime federal as práticas de cruzar fronteiras estatais para praticar violência contra a mulher e os atos de violação de ordens de proteção interestaduais (ESTADOS UNIDOS DA AMÉRICA, 2020).

Entre os serviços sociais adquiridos pelas mulheres vítimas de violência em razão da referida lei, destaca-se o fornecimento de exames gratuitos para vítimas de abuso sexual, a gratuidade nos processos ou requerimento de ordens de proteção para casos de violência doméstica, assistência legal a essas mulheres, serviços para crianças e adolescentes em situação de violência familiar e o acesso aos abrigos para mulheres agredidas (ESTADOS UNIDOS DA AMÉRICA, 2018). Importante salientar também o direito constituído às mulheres de ser tratada com dignidade e com respeito a sua privacidade e o direito de ser notificada acerca das decisões judiciais sobre o acusado. Com efeito, é notável a preocupação do VAWA para garantir e promover justiça e auxílio às mulheres em situação de agressão em todas as esferas necessárias para seu bem-estar e sua saída da condição de vítima.

Outra questão relevante se refere à atenção que essa lei dá à proteção de mulheres imigrantes, grupo que possui elevada condição de vulnerabilidade em razão da xenofobia muito presente na sociedade e da dificuldade que esse público possui em obter acesso a determinados serviços públicos, ou, até mesmo, pela necessidade pelo status do marido agressor de cidadão dos EUA. Nesse sentido, essas mulheres correm ainda mais risco de serem expostas à violência doméstica. O VAWA permite que imigrantes ilegais casadas com agressores com cidadania americana se qualifiquem para pedir a cidadania, para si e seus filhos, independente do seu cônjuge apoiar seu pedido (SACCO, 2019, p.15).

Além disso, o Violence Against Women Act também fez alterações no Gun Control Act, uma lei federal dos Estados Unidos que regula o setor de armas de fogo e seus proprietários. Pessoas sujeitas a ordens de proteção ou condenadas por violência doméstica que possuírem armas de fogo em casa passaram a cometer crime federal (ESTADOS UNIDOS DA AMÉRICA, 2020).

Desde a promulgação original do VAWA, em 1994, ele já foi reautorizado três vezes desde então, em 2000, em 2005 e, quando foi sancionada pelo então presidente Obama, em 2013 (SACCO, 2019, p.15). As reautorizações da lei acrescentaram diversas medidas para reforçar o combate da violência de gênero e apoiar grupos sociais em situação de vulnerabilidade, como a comunidade LGBT, os indígenas, imigrantes, pessoas com deficiência e vítimas de tráfico. Assim, evidencia-se o elevado cuidado do Violence Against Women Act em estar em constante atualização e aprimoramento, a fim de atender as demandas sociais que surgem com o passar dos anos e destacar a proteção legal às parcelas da sociedade em maior condição de vulnerabilidade e desamparo.

O Violence Against Women Reauthorization Act of 2019 foi o mais recente aprovado pela "House of Representatives" (parte no Congresso americano), porém ainda não foi sancionado. Nas questões consideradas para a efetivação dessa reautorização do VAWA, há,

\footnotetext{
${ }^{8}$ Em 2000, a disposição que permitia o processo civil federal para crimes de violência de gênero foi considerada inconstitucional no caso Estados Unidos vs. Morrison.
} 
entre outras, o aprimoramento de ferramentas judiciais para a aplicação da lei, a proposta de melhorias na coleta de dados sobre violência doméstica, perseguições e estupro, bem como novas medidas voltadas a promover maior proteção das indígenas. O VAWA 2019 também inclui novas abordagens para garantir assistência às vítimas, reautorizamentos de financiamentos para diversos programas VAWA, a autorização de novos programas, a abordagem sobre bullying unida a educação preventiva e o ato de incluir que pessoas condenadas por violência no namoro, ou que estão sujeitas a ordens de proteção Ex Parte ${ }^{9}$ estejam proibidas de ter porte de armas de fogo (ESTADOS UNIDOS DA AMÉRICA, 2019). Em razão de grupos defensores do direito às armas, os esforços para a reautorização do Violence Against Women Reauthorization Act of 2019 foram interrompidos, todavia, requer ressaltar o grande apoio que Joe Biden, atual presidente dos Estados Unidos, direciona à reautorização da referida lei.

\section{CONCLUSÃO}

A violência doméstica, expressão de uma intolerância de gênero que persiste desde a antiguidade, se encontra naturalizada na sociedade atual, que a identifica como algo que está na ordem das coisas e que deve ser assunto pertencente apenas ao ambiente familiar. A transformação dessa mentalidade e cultura ultrapassada ocorre em passos lentos e com desafios, haja vista os séculos de desproteção da mulher, até mesmo pelo próprio direito, que costumava permitir e defender inúmeras desigualdades entre os sexos ao longo da história. A partir dessa extensa herança histórica de desvalorização, a necessidade de reverter esse cenário tornou-se de máxima urgência na atualidade, ações governamentais para controlar a discriminação de gênero e a consequente prática de violência contra a mulher foram essenciais em todos os lugares do mundo. A análise dessas ações tomadas em diferentes países, que foram expressas, principalmente, na criação de leis, tem o poder de identificar seus potenciais e suas falhas, bem como permitir mais estudos para o desenvolvimento de estratégias a fim de erradicar esse tipo de violência.

A comparação entre as medidas legais brasileiras e norte-americanas, considerando principalmente a Lei Maria da Penha e o Violence Against Women Act, possibilitou identificar aspectos comuns e destoantes entre as legislações analisadas. Destaca-se, primeiramente, a diferença entre os conceitos de violência doméstica estabelecidos por cada lei, enquanto a Lei $\mathrm{n}^{\circ} 11.340 / 06$ estabelece como crime de violência doméstica toda agressão exercida por parceiro de relação íntima de afeto, abrangendo violência nas relações matrimoniais, nas de namoros e, por meio da definição de violência psicológica, engloba o crime de perseguição. O Violence Against Women especifica em seu texto não apenas a violência doméstica, mas também a violência no namoro e a perseguição. Além disso, é válido ressaltar os momentos em que as referidas leis foram desenvolvidas, realçando o grande atraso brasileiro em mais de 10 anos em comparação com a lei americana para combater esse tipo de violência, que foi criada em 1994 nos EUA.

Outra questão divergente se refere à determinação americana de realizar reautorizações no VAWA a cada cinco anos, medida que não é observada com a Lei Maria da Penha. Tal prática contribui para que as respostas legais a crimes de violência contra a mulher estejam em constante inovação e em harmonia com as demandas que surgem na sociedade, entretanto, colocam em risco a efetividade dessa legislação caso ela não tenha sua atualização aprovada, como ocorreu no ano de 2019. Há também na mencionada lei norte-americana, diferentemente

\footnotetext{
${ }^{9}$ Uma Ordem de Proteção Ex Parte é uma ordem temporária concedida quando um juiz acredita que há perigo imediato ou presente de abuso contra a vítima.
} 
da lei brasileira, o estabelecimento de muitos financiamentos federais para atender diversos programas que visam assistir e amparar as vítimas em todos os aspectos necessários e em todas as regiões do país, efetivando, assim, as determinações da lei.

As semelhanças que podem ser observadas entre ambas as legislações são inúmeras, com destaque para a elevada preocupação para com a emissão de ordens de proteção, que são emitidas com urgência quando necessárias, e são reconhecidas em todo o território dos países. Ademais, tanto no Brasil, quanto nos EUA, é dada a devida atenção para impedir a posse de armas de fogo por pessoas que cometem crime de violência doméstica. A Lei $n^{\circ} 11.340$ e a VAWA também se assemelham no que tange à determinação de serviços gratuitos a mulheres em situação de violência familiar, tanto no setor de saúde, quanto no setor jurídico. Outras medidas contra a violência doméstica também são verificadas nos dois textos legais, como o estabelecimento de educação preventiva e conscientização, a determinação de que sejam feitos estudos e pesquisas sobre essa problemática e o foco em capacitar os profissionais para um melhor atendimento às mulheres em condição de violência.

Com efeito, embora a Lei Maria da Penha e o Violence Against Women Act possuam papéis diferentes na criação do direito em cada país, ao considerar as diferenças existentes entre os sistemas jurídicos, constata-se que tanto para o Brasil, quanto para os Estados Unidos, as respectivas leis analisadas foram o marco inicial do combate à violência doméstica em suas nações e possuem uma imensa importância para promover dignidade e proteção às mulheres.

\section{REFERÊNCIAS}

BOURDIEU, Pierre. A dominação masculina, a condição feminina e a violência simbólica. 17. ed. Rio de Janeiro: Bertrand Brasil, 2020.

BRASIL. Lei $\mathbf{n}^{\circ}$ 11.340, de 7 de agosto de 2006. Cria mecanismos para coibir a violência doméstica e familiar contra a mulher, nos termos do $\S 8^{\circ}$ do art. 226 da Constituição Federal, da Convenção sobre a Eliminação de Todas as Formas de Discriminação contra as Mulheres e da Convenção Interamericana para Prevenir, Punir e Erradicar a Violência contra a Mulher; dispõe sobre a criação dos Juizados de Violência Doméstica e Familiar contra a Mulher; altera o Código de Processo Penal, o Código Penal e a Lei de Execução Penal; e dá outras providências. Brasília, 7 de agosto de 2006. Disponível em: http://www.planalto.gov.br/ccivil_03/_ato2004-2006/2006/lei/l11340.htm. Acesso em: 12 nov. 2020.

BRASIL. Lei $\mathbf{n}^{\circ}$ 13.104, de 9 de março de 2015. Altera o art. 121 do Decreto-Lei ${ }^{\circ} 2.848$, de 7 de dezembro de 1940 - Código Penal, para prever o feminicídio como circunstância qualificadora do crime de homicídio, e o art. $1^{\circ}$ da Lei $\mathrm{n}^{\circ} 8.072$, de 25 de julho de 1990, para incluir o feminicídio no rol dos crimes hediondos. Brasília, 7 de agosto de 2006. Disponível em:

http://www.planalto.gov.br/ccivil_03/_ato2015-2018/2015/lei/113104.htm. Acesso em: 13 Nov. 2020.

BRASIL. Decreto-lei $\mathbf{n}^{\circ} \mathbf{2 . 8 4 8}$, de 7 de dezembro de 1940. Código Penal. Rio de Janeiro, 7 de dezembro de 1940. Disponível em: http://www.planalto.gov.br/ccivil_03/decretolei/del2848compilado.htm. Acesso em: 13 nov. 2020.

BRASIL. Ministério Público do Pará. Cartilha de Proteção à Mulher: ações para 
o enfrentamento à violência doméstica e familiar. Belém, 2020. Disponível em:

https://alepa.pa.gov.br/downloads/cartilha-mulher-2.pdf. Acesso em: 13 nov. 2020.

BRASIL. Senado Federal. Violência Doméstica e Familiar Contra a Mulher. Secretária de Transparência Datasenado, 12 mar. 2013. Disponível em:

https://www.senado.gov.br/senado/datasenado/pdf/datasenado/DataSenado-Pesquisa-

Violencia_Domestica_contra_a_Mulher_2013.pdf. Acesso em: 10 nov. 2020

BRASIL. Superior tribunal federal. Proteção da mulher, Jurisprudência do STF e

Bibliografia temática. Brasília: STF, Secretaria de Documentação, 2019. (143 p.), ISBN: 978-65-87125-00-8. Disponível em:

http://www.stf.jus.br/arquivo/cms/publicacaoPublicacaoTematica/anexo/protecao_da_mulher. pdf. Acesso em: 7 nov. 2020

CERQUEIRA, Daniel; MOURA, Rodrigo; PASINATO, Wânia. Participação no mercado de trabalho e violência doméstica contra as mulheres no Brasil. Instituto de Pesquisa Econômica Aplicada, Brasília: Rio de Janeiro: Ipea, 2019. ISSN 1415-4765. Disponível em: https://www.ipea.gov.br/portal/images/stories/PDFs/TDs/td_2501.pdf. Acesso em: 15 nov. 2020.

DAVID, RENÉ. Os grandes sistemas do direito contemporâneo. 4. ed. São Paulo: Martins Fontes. 2002.

DOCHLER, Jennifer C. Opinion: The Violence Against Women Act is 26 years young and still going strong. The Missouri Times Magazine, Jefferson City, 2020. Disponível em: https://issuu.com/missouritimesmagazine/docs/final_-_30_under_30_magazine. Acesso em: 30 out. 2020

ESTADOS UNIDOS DA AMÉRICA. Office of Majority Leader Steny H.Hoyer. The Bipartisan Violence Against Women Reauthorization Act of 2019, 4 de maio de 2019. Disponível em:

https://www.majorityleader.gov/sites/democraticwhip.house.gov/files/VAWA\%20One\%20Pa ger\%20PDF.pdf. Acesso em 12 nov. 2020.

ESTADOS UNIDOS DA AMÉRICA. Office on Women's Health. Laws on violence against women. Washington, 11 out. 2018. Disponível em:

https://www.womenshealth.gov/relationships-and-safety/get-help/laws-violence-againstwomen. Acesso em: 7 nov 2020.

ESTADOS UNIDOS DA AMÉRICA. Título 34 do United State Code, §12291. 1994. Disponível em: https://www.govinfo.gov/content/pkg/USCODE-2017-title34/pdf/USCODE2017-title34-subtitleI-chap121-subchapIII.pdf. Acesso em: 11 nov. 2020

ESTADOS UNIDOS DA AMÉRICA. United States Attorney's Office for the Western District Of Tennessee. Federal Domestic Violence Laws, 26 maio 2020. Disponível em: https://www.justice.gov/usao-wdtn/victim-witness-program/federal-domestic-violence-laws. Acesso em: 7 nov. 2020. 
FREIRE, Nilcéa. Exposição de motivos 016/- SPM/PR. Item 16. Brasília: Presidência da República. Secretaria Especial de Políticas para as Mulheres, 16 nov. 2004. Disponível em: https://www.camara.leg.br/proposicoesWeb/prop_mostrarintegra?codteor=256085. Acesso em: 10 nov. 2020.

LAW, Tara. The Violence Against Women Act Was Signed 25 Years Ago: Here's How the Law Changed American Culture. TIME, 26 jun. 2019. Disponível em: https://time.com/5675029/violence-against-women-act-history-biden/. Acesso em: 7 nov. 2020.

MACKINNON, Catharine. Reflections on Sex Equality under the Law. Yale Law Journal. Yale, 100: 5, 1991, p. 1281-1328. Disponível em:

https://digitalcommons.law.yale.edu/cgi/viewcontent.cgi?referer=https://www.google.com/\&h ttpsredir=1\&article=7341\&context=ylj. Acesso em: 28 ago. 2020.

MORGAN, E. Rachel, TRUMAN L. Jennifer. Criminal Victimization, 2019. Setembro 2020. Disponível em: https://www.bjs.gov/content/pub/pdf/cv19.pdf. Acesso em: 30 out. 2020.

NATIONAL DOMESTIC VIOLENCE HOTLINE. Violence Against Women Act (VAWA). Disponível em: https://www.thehotline.org/resources/violence-against-women-act-vawa/. Acesso em: 30 out. 2020.

NOW. Violence Against Women in the United States: Statistics, 2020. Disponível em: https://now.org/resource/violence-against-women-in-the-united-states-statistic/. Acesso em: 7 nov. 2020.

PORTUGAL. Ordenações Filipinas. Livro 5, tit. 37/38,1595 Disponível em: http://www1.ci.uc.pt/ihti/proj/filipinas/15p1188.htm. Acesso em: 12 nov. 2020.

REALE, Miguel. Lições preliminares de Direito. 27. ed. São Paulo: Saraiva, 2002.

SACCO, Lisa N. The Violence Against Women Act (VAWA): Historical Overview, Funding, and Reauthorization. The Congressional Research Service (CRS), 23 abril 2019. Disponível em:

https://www.everycrsreport.com/files/20190423_R45410_672f9e33bc12ac7ff52d47a8e6bd97 4d96e92f02.pdf. Acesso em: 30 out 2020.

SILVA, Danielle Martins. Violência doméstica na Lei Maria da Penha. Reflexos da visibilidade jurídica do conflito familiar de gênero. Revista Jus Navigandi, Teresina, ano 13, n. 1874, 2008. Disponível em: https://jus.com.br/artigos/11614. Acesso em: 28 out. 2020

SILVA, K. Cristian; SEABRA, T. Débora; JÚNIOR, A. Luiz. Feminismo, violência e poder: Uma análise histórico-jurídica da trajetória e dos documentos que culminaram na Lei Maria Da Penha e no Feminicídio. Cadernos do Programa de Pós-Graduação em Direito, Porto Alegre, vol. XI, número 3, p. 301-306, 2016. Disponível em:

https://www.seer.ufrgs.br/ppgdir/article/view/66459/40479. Acesso em: 09 nov. 2020 
UNITED NATION ENTITY FOR GENDER EQUALITY AND THE EMPOWERMENT OF WOMEN (UN Women). Ending violence against women: From words to action. Study of the Secretary-General, 2006. ISBN/ISSN: 9789211302530. Disponível em:

https://www.unwomen.org/en/digital-library/publications/2006/1/ending-violence-againstwomen-from-words-to-action-study-of-the-secretary-general. Acesso em: 29 out. 2020

WOMENSLAW.ORG. Domestic Violence/Dating Violence, 2019. Disponível em: https://www.womenslaw.org/about-abuse/forms-abuse/domestic-violencedating-violence. Acesso em: 29 out. 2020

ZAGANELLI, Margareth; SALARDI, Silvia. The European and Italian cases of violence against women: between repression and prevention. Revista Jurídica da Presidência, Brasília, v. 22, n. 126, p. 48-65, Fev. /Maio 2020. Disponível em:

https://revistajuridica.presidencia.gov.br/index.php/saj/article/view/2098. Acesso em: 22 out. 2020. 